Original Article

\title{
The effect of mechanical massage on early outcome after total knee arthroplasty: a pilot study
}

\author{
Sun Mi Kim, MD ${ }^{1)}$, SAng-Rim Kim, MD, PhD²), Yong Ki Lee, $\mathrm{MD}^{1)}$, \\ Bo Ryun KIm, MD, PhD ${ }^{1)}$, Eun Young Han, MD ${ }^{1)}$ \\ 1) Department of Rehabilitation Medicine, Jeju National University Hospital, Jeju National University \\ School of Medicine, Republic of Korea \\ 2) Department of Orthopaedic Surgery, Jeju National University Hospital, Jeju National University \\ School of Medicine: 15 Aran 13-gil, Jeju 690-767, Republic of Korea
}

\begin{abstract}
Purpose] The aim of this study was to evaluate the efficacy of mechanical massage via Endermologie ${ }^{\circledR}$ after total knee arthroplasty in reducing edema and pain and improving knee range of motion, in the early postoperative period. [Subjects and Methods] Eighteen patients with knee edema following total knee arthroplasty were randomly assigned to the intervention group $(n=8)$ or the control group $(n=10)$. The intervention group received mechanical massage therapy using Endermologie ${ }^{\circledR}$ and the control group received conventional physical therapy for 20 minutes a day, 5 times a week from the seventh day postsurgery. Clinical assessments included active knee flexion and extension range of motion, knee pain using a numeric rating scale, the operated limb circumference, the soft tissue cross-sectional area using ultrasonography, the extracelluar fluid volume, and single frequency bioimpedance analysis at $5 \mathrm{kHz}$ using bioelectrical impedance spectroscopy. [Results] Both groups showed significant reduction in edema and pain, and improvement in active knee flexion at the end of treatment. There were no significant inter-group differences before or after treatment. [Conclusion] Mechanical massage could be an alternative way of managing knee edema after total knee arthroplasty in early postoperative recovery.

Key words: Total knee arthroplasty, Edema, Mechanical massage
\end{abstract}

(This article was submitted Jul. 2, 2015, and was accepted Aug. 5, 2015)

\section{INTRODUCTION}

Total knee arthroplasty (TKA) is considered to be a successful orthopedic procedure for pain relief and improvement of the physical function of patients with severe knee osteoarthritis ${ }^{1)}$. However, the edematous response to traumatic orthopedic procedures such as TKA creates incompetence in the lymphatic system and persistent edema ${ }^{2}$. Therefore, TKA is followed by a convalescence period, during which undesirable sequelae such as edema and postoperative pain may limit early functional recovery. The effect of swelling, inflammation, and pain on muscle inhibition has been well documented ${ }^{3,4)}$.

Endermologie ${ }^{\circledR}$ delivers mechanical massage to the limb via two motorised, cylindrical skin rollers which pick up and massage the skin inside its treatment head. Previous studies of this equipment have shown that it improves superficial lymphatic drainage and lymphatic transport capacity ${ }^{5}$. To our knowledge, the benefits of Endermologie ${ }^{\circledR}$ as an edema treatment method following TKA have not been evaluated.

*Corresponding author. Sang-Rim Kim (E-mail: kimsros@, jejunu.ac.kr)

(C2015 The Society of Physical Therapy Science. Published by IPEC Inc. This is an open-access article distributed under the terms of the Creative Commons Attribution Non-Commercial No Derivatives (by-ncnd) License $<$ http://creativecommons.org/licenses/by-nc-nd/3.0/>.
The aims of this study were to investigate the efficacy of Endermologie $^{\circledR}$, in the early postoperative period after TKA, in reducing edema and knee pain, and improving active knee range of motion in comparison with conventional postoperative care using various objective outcome measurements.

\section{SUBJECTS AND METHODS}

Eighteen patients with end-stage knee osteoarthritis (5 males and 13 females; mean age, $73.4 \pm 5.7$ years) scheduled for primary unilateral TKA between August 2014 and May 2015 were selected for this study. Patients were excluded if they had an active infection, major cardiac pathology, or thrombus or venous obstruction that was prediagnosed or revealed on a routine preadmission hospital screening ${ }^{6}$.

This study was approved by the Ethics Committee of the Jeju National University of Korea and written consent to participication in the study was obtained from all of the subjects in accordance with the Declaration of Helsinki.

This was a randomized, single-blind study. Participants were randomly allocated to the two study groups. The randomization was performed using a sealed envelope technique. Eight patients were allocated to the intervention group, and ten patients to the control group. All patients underwent TKA performed by a single experienced orthopedic surgeon specializing in joint replacement surgery. A midline incision and the medial parapatellar retinacular approach were used in all cases. On the seventh day postsurgery, patients 
allocated to the intervention group underwent a 20 minutes of Endermologie ${ }^{\circledR}$ therapy on the operated limb applied by a physical therapist trained in the technique; the Cellu-M50 LPG Systems device (LPG Systems, Valence, France) was used. The procedure consists of a tissue mobilization process between two rollers, creating a skin fold and stretching the underlying tissue to improve superficial lymphatic drainage. Focus was initially on the proximal tissue, gradually moving distally to the area around the knee, popliteal region, and back proximally, to optimize the lymphatic system by clearing lymphatic drainage in areas adjacent to the regions of knee edema, and develop new pathways for travel ${ }^{2,7)}$. This process of working proximal to distal and then distal to proximal was repeated 3 to 4 times over the 20 -minute treatment period. Participants in the control group received conventional physiotherapy including cryotherapy and pneumatic leg pump therapy for the same amount of time as the intervention group. Both groups received their treatments 5 days a week ( 5 treatment sessions in total). Postoperative inpatient rehabilitation such as isometric contraction of the quadriceps and gluteal musculature was standard for all of the study patients.

The following clinical measures were evaluated before and after one week of treatment by the patient's allocated physician who was blinded to the treatments. First, active knee flexion and extension were measured using a handheld goniometer, creating an angle made by three anatomical landmarks: the greater trochanter of the femur at the hip, the lateral femoral condyle at the knee, and the lateral malleolus at the ankle ${ }^{7)}$. Second, knee pain severity was evaluated using a numeric rating scale (NRS), on a whole number rating scale from 0 (no pain) to 10 (worst pain). Third, the circumferences of the operated limbs at $10 \mathrm{~cm}$ above and below the midpatella were assessed (suprapatellar circumference and infrapatellar circumference). Measurements were taken twice with a tape measure at each site, and the minimum value was recorded $^{8}$. Fourth, ultrasonography was performed on the operated limb of each participant using a $9.0 \mathrm{MHz}$ transducer (GE Healthcare, Milwaukee, Wisconsin). The superior, medial, inferior and lateral directions were marked to measure the desired cross section at $10 \mathrm{~cm}$ above the midpatella. The soft tissue cross-sectional area was calculated as described by Hwang et $\mathrm{al}^{9}$ ). Finally, the ratio of extracellular fluid (ECF) volume, and the ratio of the single frequency bioimpedance analysis (SFBIA) value at $5 \mathrm{kHz}$ of the bilateral lower extremities was evaluated using bioelectrical impedance spectroscopy (Inbody 720 Biospace, Seoul, South Korea) ${ }^{10)}$. The ECF ratios of the operated to the non-operated side and the non-operated to the operated side ratio of the SFBIA value at $5 \mathrm{kHz}$ were calculated. A lower value of SFBIA at $5 \mathrm{kHz}$ suggests that there is fluid in the extracellular space, and higher ratios of both calculated ECF and SFBIA suggest that there is more ECF in the operated limb ${ }^{10)}$.

The change in each outcome measure from pre- to posttreatment was evaluated separately in each group using the Wilcoxon signed rank test. The change in each outcome measure from pre- to post- treatment was compared between the two groups using the Mann-Whitney test. A p value less than 0.05 was considered significant. Statistical analyses
Table 1. Baseline demographic characteristics of the participants

\begin{tabular}{lcc}
\hline Variables & $\begin{array}{c}\text { Intervention } \\
\text { group }\end{array}$ & $\begin{array}{c}\text { Control } \\
\text { group }\end{array}$ \\
\hline Lesion side, right/left & $4 / 4$ & $4 / 6$ \\
Gender, males/females & $3 / 5$ & $2 / 8$ \\
Age (years) & $70.8 \pm 5.4$ & $75.6 \pm 5.1$ \\
Height $(\mathrm{cm})$ & $155.9 \pm 8.2$ & $155.2 \pm 7.9$ \\
Weight $(\mathrm{kg})$ & $64.6 \pm 6.9$ & $66.1 \pm 10.0$ \\
Body mass index $\left(\mathrm{kg} / \mathrm{m}^{2}\right)$ & $26.7 \pm 3.2$ & $27.3 \pm 2.8$ \\
\hline
\end{tabular}

Values are numbers or mean \pm standard deviation

were performed using SPSS for Windows version 20 (IBMSPSS, Inc., Chicago, IL, USA).

\section{RESULTS}

Patient demographics were similar between the two groups and are summarized in Table 1. The intervention group showed significant improvement from pre- to posttreatment in active knee flexion, knee pain, both circumferences of the operated limb and cross-sectional area of soft tissue at $10 \mathrm{~cm}$ above the midpatella, and the ratio of the SFBIA value at $5 \mathrm{kHz}$ (Table 2). No statistically significant between-group differences were found for any of the variables before and after treatment; however, the infrapatellar circumference of the surgical limb showed a significant reduction only in the control group (Table 2). Although not statistically significant, a decreasing trend was exhibited for the infrapatellar circumference in the intervention group.

\section{DISCUSSION}

This is the first study to investigate the therapeutic effect of mechanical massage for patients with knee edema after TKA in the early postoperative period, and to compare the effectiveness of conventional physical therapy and mechanical massage using objective measures of soft tissue edema change.

The findings of the present study are in line with the findings of Ebert et al., who also studied the efficacy of massage intended to encourage the natural drainage of the lymph in early outcomes after TKA, in addition to conventional care $^{7)}$. However, the present study is the first to show the effect of mechanical massage via Endermologie ${ }^{\circledR}$ alone in the absence of other physical therapies. In addition, the objective measurements of the present study included the amount of soft tissue in the cross-sectional area around the knee as assessed by using ultrasonography, and the ratio of extracelluar fluid volume and the ratio of SFBIA value at 5 $\mathrm{kHz}$, as well as limb circumference, and is, therefore, methodologically different from the study of Ebert et al.

Massage is known to manipulate the attachments below the skin, eliciting modification in the connective tissues ${ }^{11)}$. Endermologie $^{\circledR}$ is an original noninvasive technique, consisting of a delicate and reproducible mechanical massage, and elicits a profound physiological alteration in lymphatic flow $^{5,12)}$. A previous study demonstrated the effect of me- 
Table 2. Changes in knee range of motion, pain and edema of the intervention and control groups before and after treatment

\begin{tabular}{|c|c|c|c|c|c|c|c|}
\hline \multirow[b]{2}{*}{ Variables } & \multicolumn{3}{|c|}{ Intervention group } & \multicolumn{3}{|c|}{ Control group } & \multirow{2}{*}{$\begin{array}{l}\text { Intergroup } \\
\text { difference }\end{array}$} \\
\hline & Before & After & $\begin{array}{l}\text { Intragroup } \\
\text { difference }\end{array}$ & Before & After & $\begin{array}{l}\text { Intragroup } \\
\text { difference }\end{array}$ & \\
\hline e-AROM $\left({ }^{\circ}\right)$ & $-13.1 \pm 7.0$ & $-11.9 \pm 6.5$ & 0.16 & $-14.0 \pm 8.1$ & $-13.0 \pm 6.7$ & 0.08 & 0.82 \\
\hline $\mathrm{f}-\mathrm{AROM}\left({ }^{\circ}\right)$ & $73.1 \pm 19.3$ & $88.8 \pm 18.7$ & $0.02 *$ & $74.0 \pm 11.3$ & $91.0 \pm 10.8$ & $0.01^{*}$ & 0.79 \\
\hline NRS & $3.5 \pm 0.5$ & $2.1 \pm 0.8$ & $0.02 *$ & $3.7 \pm 0.9$ & $2.6 \pm 0.5$ & $0.01 *$ & 0.34 \\
\hline $\mathrm{SC}(\mathrm{cm})$ & $42.3 \pm 3.6$ & $41.4 \pm 3.3$ & $0.03 *$ & $43.7 \pm 3.3$ & $41.8 \pm 2.8$ & $0.01 *$ & 0.18 \\
\hline $\mathrm{IC}(\mathrm{cm})$ & $33.8 \pm 2.0$ & $32.9 \pm 2.2$ & 0.06 & $34.9 \pm 2.6$ & $34.2 \pm 2.3$ & $0.04^{*}$ & 0.74 \\
\hline $\mathrm{CSA}\left(\mathrm{mm}^{2}\right)$ & $49.8 \pm 13.1$ & $39.9 \pm 13.2$ & $0.01^{*}$ & $50.7 \pm 9.1$ & $43.7 \pm 8.9$ & $0.01 *$ & 0.31 \\
\hline RECF (\%) & $104.3 \pm 2.9$ & $103.3 \pm 1.8$ & 0.23 & $104.4 \pm 2.4$ & $101.4 \pm 6.9$ & 0.18 & 0.65 \\
\hline RSFBIA (\%) & $134.8 \pm 16.0$ & $123.6 \pm 6.9$ & $0.04 *$ & $136.4 \pm 17.3$ & $126.1 \pm 14.1$ & $0.01 *$ & 0.76 \\
\hline
\end{tabular}

Values are mean \pm standard deviation.

e-AROM: extension active range of motion; f-AROM: flexion active range of motion; NRS: numeric rating scale; SC: suprapatellar circumference; IC: infrapatellar circumference; CSA: cross-sectional area of soft tissue; RECF: the ratio of extracelluar fluid volume; RSFBIA: the ratio of single frequency bioimpedance analysis $* p<0.05$

chanical massage via Endermologie ${ }^{\circledR}$ on the treatment of limb-swelling in patients with secondary arm lymphoedema $^{5}$. In line with the methods of this previous study, we included Endermologie ${ }^{\circledR}$ to treat limb edema. However, there is a difference in the populations of the two trials, as the subjects in the study of Moseley et al., had secondary arm lymphoedema ${ }^{5)}$, whereas subjects in the present study had knee edema following TKA.

Knee edema is a normal body response to surgical trauma and occurs in most patients who undergo TKA ${ }^{13,14)}$. The consequences of knee edema are pain, inflammation, decreased range of motion, quadriceps inhibition, functional limitation and a delay in rehabilitation ${ }^{13,15)}$. In addition, fear of symptom aggravation typically precludes progressive strength training early after TKA ${ }^{16)}$. Despite the influence of knee edema on the rehabilitation process, little research has been conducted on knee edema following TKA. Our results reveal that Endermologie ${ }^{\circledR}$ is beneficial in the short term at least. There is evidence to support the effect of early and intensive exercise after TKA in the prevention of early loss of muscle strength and function after surgery ${ }^{3,17)}$. Knee edema management would contribute to patients' participation in early postoperative rehabilitation. Therefore, adopting mechanical massage treatment in the early postoperative period could potentially benefit patients' rehabilitation.

Our research has several notable findings. It is the first study to provide objective evidence of edema reduction by mechanical massage using ultrasonography and bioelectrical impedance spectroscopy. Muscular atrophy is substantial following TKA; however, limb circumference measurements do not allow for the differentiation between respective variations in edema and muscular mass ${ }^{18)}$. In contrast, ultrasonography and bioelectrical impedance spectroscopy can measure limb edema independently, and have excellent reliability and accuracy $\left.{ }^{9}, 13\right)$. Also, Endermologie ${ }^{\circledR}$ was used as a specific type of mechanical massage in comparison with other conventional physical therapies. In addition, our findings open a new possibility in the early management of knee edema after TKA to improve the early rehabilitation process. A significant improvement in active knee flexion was observed at the follow-up assessment time prior to hospital discharge, after one week of Endermologie ${ }^{\circledR}$ treatment sessions, in the present study. Findings from previous studies highlighted the importance of early attainment of active knee flexion for long-term actual and perceived benefits ${ }^{7}$.

This study had several limitations. First, this was a pilot study including a small number of patients that aimed to evaluate the effect of mechanical massage on knee edema early after TKA. Second, there was no follow-up; therefore, the long-term effects of mechanical massage on edema, pain and range of motion after discharge remain unclear.

In conclusion, the results of this pilot study indicate that mechanical massage via Endermologie ${ }^{\circledR}$ is effective in knee edema treatment following TKA, leading to better early outcomes for the patients.

\section{ACKNOWLEDGEMENT}

This work was supported by the research grant of the Jeju National University Hospital in 2014.

\section{REFERENCES}

1) Maruyama $T$, Sawada $Y$, Kubo S, et al.: Postoperative changes in knee joint function of total knee arthroplasty patients. J Phys Ther Sci, 2011, 23: 719-724. [CrossRef]

2) Howard SB, Krishnagiri S: The use of manual edema mobilization for the reduction of persistent edema in the upper limb. J Hand Ther, 2001, 14: 291-301. [Medline] [CrossRef]

3) Bandholm $T$, Kehlet $H$ : Physiotherapy exercise after fast-track total hip and knee arthroplasty: time for reconsideration? Arch Phys Med Rehabil, 2012, 93: 1292-1294. [Medline] [CrossRef]

4) Rice DA, McNair PJ: Quadriceps arthrogenic muscle inhibition: neural mechanisms and treatment perspectives. Semin Arthritis Rheum, 2010, 40: 250-266. [Medline] [CrossRef]

5) Moseley AL, Esplin M, Piller NB, et al.: Endermologie (with and without compression bandaging) - a new treatment option for secondary arm lymphedema. Lymphology, 2007, 40: 129-137. [Medline]

6) Ernst E: The safety of massage therapy. Rheumatology (Oxford), 2003, 42: 1101-1106. [Medline] [CrossRef]

7) Ebert JR, Joss B, Jardine B, et al.: Randomized trial investigating the efficacy of manual lymphatic drainage to improve early outcome after total knee arthroplasty. Arch Phys Med Rehabil, 2013, 94: 2103-2111. [Medline] [CrossRef] 
8) Brown J: A clinically useful method for evaluating lymphedema. Clin J Oncol Nurs, 2004, 8: 35-38. [Medline] [CrossRef]

9) Hwang JH, Lee CH, Lee HH, et al.: A new soft tissue volume measurement strategy using ultrasonography. Lymphat Res Biol, 2014, 12: 89-94. [Medline] [CrossRef]

10) Kim L, Jeon JY, Sung IY, et al.: Prediction of treatment outcome with bioimpedance measurements in breast cancer related lymphedema patients. Ann Rehabil Med, 2011, 35: 687-693. [Medline] [CrossRef]

11) Marques MA, Combes $M$, Roussel $B$, et al.: Impact of a mechanical massage on gene expression profile and lipid mobilization in female gluteofemoral adipose tissue. Obes Facts, 2011, 4: 121-129. [Medline] [CrossRef]

12) Gordon C, Emiliozzi C, Zartarian M: Use of a mechanical massage technique in the treatment of fibromyalgia: a preliminary study. Arch Phys Med Rehabil, 2006, 87: 145-147. [Medline] [CrossRef]

13) Pichonnaz C, Bassin JP, Currat D, et al.: Bioimpedance for oedema evaluation after total knee arthroplasty. Physiother Res Int, 2013, 18: 140-147.
[Medline] [CrossRef]

14) Marulanda GA, Krebs VE, Bierbaum BE, et al.: Hemostasis using a bipolar sealer in primary unilateral total knee arthroplasty. Am J Orthop, 2009, 38: E179-E183. [Medline]

15) Gao FQ, Li ZJ, Zhang K, et al.: Risk factors for lower limb swelling after primary total knee arthroplasty. Chin Med J (Engl), 2011, 124: 3896-3899. [Medline]

16) Jakobsen TL, Husted H, Kehlet H, et al.: Progressive strength training (10 RM) commenced immediately after fast-track total knee arthroplasty: is it feasible? Disabil Rehabil, 2012, 34: 1034-1040. [Medline] [CrossRef]

17) Bade MJ, Stevens-Lapsley JE: Restoration of physical function in patients following total knee arthroplasty: an update on rehabilitation practices. Curr Opin Rheumatol, 2012, 24: 208-214. [Medline] [CrossRef]

18) Warren AG, Brorson $\mathrm{H}$, Borud LJ, et al.: Lymphedema: a comprehensive review. Ann Plast Surg, 2007, 59: 464-472. [Medline] [CrossRef] 